\title{
Gastric Langerhans Cell Histiocytosis: Case Report and Review of the Literature
}

\author{
So Jung Lee ${ }^{1,2} \cdot$ Chung Su Hwang ${ }^{1,2} \cdot$ Gi Young Huh ${ }^{1,2}$. Chang Hun Lee ${ }^{1,2}$. Do Youn Park ${ }^{1,2}$ \\ 1'Department of Pathology, Pusan National University Hospital, Pusan National University School of Medicine, Busan; \\ ${ }^{2}$ Biomedical Research Institute, Pusan National University Hospital, Busan, Korea
}

Langerhans cell histiocytosis (LCH) is a rare disease of unknown etiology and is characterized by a clonal proliferation of Langerhans cells. ${ }^{1}$ The clinical presentation of $\mathrm{LCH}$ is variable, ranging from single organ to multisystem involvement; patients may experience benign to life-threatening outcomes. ${ }^{1}$ Localization of $\mathrm{LCH}$ to the stomach is extremely rare and is most often found in pediatric patients with systemic disease. ${ }^{2}$ Here we present a case of localized LCH to the stomach in a 64-year-old man who underwent a complete resection of the lesion by endoscopic submucosal dissection (ESD).

\section{CASE REPORT}

A 64-year-old man was referred to a gastroenterologist for further evaluation of an abnormality found during an upper gastrointestinal examination. This patient had nothing remarkable in his medical history except medical treatment for hyperthyroidism. Esophagogastroduodenoscopy revealed an elevated mucosal lesion approximately $1 \mathrm{~cm}$ in size in the gastric fundus (Fig. 1A). The surface of the lesion was smooth with focal erosion. Microscopic examination of the endoscopic biopsy specimen revealed increased eosinophilia, and a cluster of histiocytic cells infiltrated the lamina propria and were mixed with lymphocytes, neutrophils, and plasma cells (Fig. 1C). The histiocytic cells had elongated nuclei, intranuclear grooves, and irregular nuclear mem-

\section{Corresponding Author}

Do Youn Park, MD, PhD

Department of Pathology, Pusan National University Hospital, Pusan National University School of Medicine, 179 Gudeok-ro, Seo-gu, Busan 49241, Korea

Tel: +82-51-240-7422, Fax: +82-51-242-7422, E-mail: pdy220@pusan.ac.kr

Received: February 3, 2015 Revised: May 4, 2015

Accepted: May 19, 2015 branes, as well as abundant fine granular eosinophilic to clear cytoplasm. Histiocytic cell clusters showed strong immunoreactivity to $\mathrm{S} 100$ and CD1a (Fig. 1D), while they were negative to cytokeratin AE1/AE3 and leukocyte common antigen. Through a combination of morphological and immunohistochemical analyses, a diagnosis of LCH was confirmed. A gastroenterologist performed ESD for complete removal of the lesion. The ESD specimen showed a very focal remnant LCH lesion that had been completely removed (Fig. 1B). Following complete resection of the gastric LCH lesion, a comprehensive evaluation was performed to determine the extent of the disease. No evidence of multisystem involvement was found. The patient's 6-month follow-up visit revealed no local or systemic recurrence, and the patient remained in good health.

\section{DISCUSSION}

LCH is a rare disease identified in both children and adults and is characterized by infiltration of histiocytic cells in various organs. ${ }^{3}$ The pathogenesis and etiology of LCH are not fully understood. ${ }^{1} \mathrm{~A}$ recent hypothesis suggests that $\mathrm{LCH}$ cells are derived from bone marrow monocyte precursors that differentiate into antigen-presenting cells (i.e., Langerhans cells or dendritic cells) in the epidermis, respiratory tract, and lymph nodes. The presence of monoclonality itself has been used as evidence that this disease is a clonal neoplastic disorder. Despite the neoplastic nature of the condition, the clinical course of LCH is heterogeneous. Therefore, treatment of $\mathrm{LCH}$ depends on the extent and severity of the disease at the time of diagnosis, which includes the number of involved organs and the presence of normal organ function. ${ }^{1}$ 

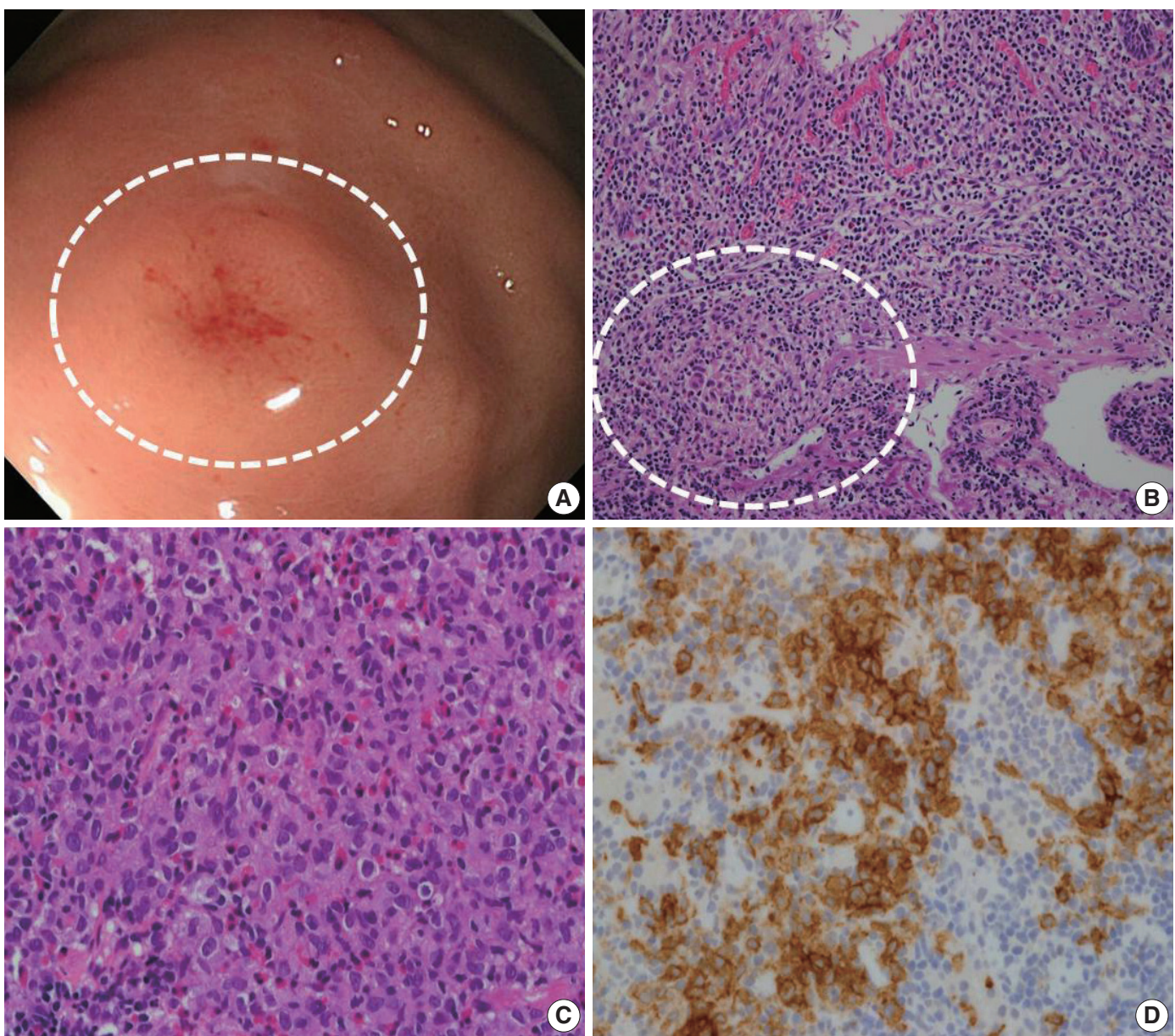

Fig. 1. Endoscopic and histologic finding of gastric Langerhans cell histiocytosis. (A) A mild elevated mucosal lesion (1 cm in size) with central erosion is observed upon gastroenteroscopy (circle). The lesion is located in the fundus of the stomach. (B) Microscopic analysis of the endoscopic submucosal dissection specimen. Focal histiocytic cell aggregates are present in the lamina propria and muscularis mucosa, with abundant eosinophils and other inflammatory cells. (C) Microscopic analysis of the endoscopic biopsy specimen reveals histiocytic cell aggregates in the lamina propria of the mucosa, with abundant eosinophil infiltration. Lymphocytes and plasma cells are also observed. The histiocytic cells show an irregular nuclear membrane and groove. These cells have abundant and granular eosinophilic to clear cytoplasm. (D) Immunohistochemistry for CD1a. The histiocytic cells show positive staining for CD1a.

Involvement of the gastrointestinal tract is very rare and has been associated with systemic involvement and poor prognosis. ${ }^{4}$ In pediatric patients, $\mathrm{LCH}$ in the gastrointestinal tract produces symptoms such as vomiting, loose stool, and abdominal pain and is related to a poor prognosis in the majority of neonatal cases; in these patients, skin lesions usually precede gastrointestinal LCH. ${ }^{4,5}$ In contrast to children, adult patients are asymptomatic and present with solitary polypoids or elevated lesions. ${ }^{4}$ Only six cases in adult of gastric LCH have been reported in the literature. $^{4,6-10}$ In contrast to pediatric LCH, adult gastric LCH appears as a unifocal disease without recurrence or progression, in a similar manner to our case (Table 1). Like many other gastric $\mathrm{LCH}$ cases, an elevated mucosal lesion was noted in our patient by the gastroenterologist, whose initial impression was a sub- mucosal tumor. Endoscopic findings of gastric LCH mucosa are sometimes confused with gastric tumors presenting as polypoids and ulcerative mucosa., ${ }^{2,4}$ Despite the absence of clinical features, gastric LCH shows the typical histological characteristics of LCH in other organs. ${ }^{3,4}$ Histologically, histiocytic cells resemble Langerhans cells of the epidermis. Langerhans cell form a sheet of islands with indistinct cell borders and abundant eosinophilic cytoplasm. Their nuclei are elongated and irregular, exhibiting vesicular chromatin with a nuclear groove and often presenting with a single prominent nucleoli. ${ }^{3,4}$ Langerhans cells are usually mixed with other inflammatory cells such as eosinophils, lymphocytes, plasma cells, and neutrophils. In the literature, predominant eosinophil infiltration has been reported in $50 \%$ of cases with gastric $\mathrm{LCH}^{4}{ }^{4}$ In a similar manner to a previous re- 
Table 1. Comparison of reported cases and presented case

\begin{tabular}{|c|c|c|c|c|c|c|c|c|c|c|}
\hline $\begin{array}{c}\text { Case } \\
\text { no. }\end{array}$ & Reference & $\begin{array}{l}\text { Age }(y r) / \\
\text { Sex }\end{array}$ & Symptom & $\begin{array}{l}\text { Endoscopic } \\
\text { finding }\end{array}$ & Site & Multiplicity & Specimen & Multisystem $^{a}$ & Outcomes & Follow-up \\
\hline 1 & $\begin{array}{l}\text { Singhi and } \\
\text { Montgomery }^{4}\end{array}$ & $68 / \mathrm{M}$ & Dysphasia & Polyp & Antrum & Solitary & Biopsy & Absent & Remission & $22 \mathrm{mo}$ \\
\hline 2 & Iwafuchi et al. ${ }^{6}$ & $49 / F$ & Asymptomatic & Sessile elevation & $\begin{array}{l}\text { Throughout the } \\
\text { stomach }\end{array}$ & Multiple & Biopsy & Absent & Remission & $5.6 \mathrm{yr}$ \\
\hline 3 & Nihei et al. ${ }^{7}$ & $47 / F$ & $\mathrm{R} / \mathrm{O}$ cancer & Flat & Body & Solitary & Resection & Absent & Remission & $20 \mathrm{mo}$ \\
\hline 5 & Lee et $a l^{9}{ }^{9}$ & $51 / \mathrm{M}$ & Asymptomatic & Elevated & Antrum & Solitary & Biopsy, ESD & Absent & Remission & $12 \mathrm{mo}$ \\
\hline 6 & Wada et al. ${ }^{10}$ & $53 / F$ & $\begin{array}{l}\text { Abdominal } \\
\text { discomfort }\end{array}$ & Polypoid & $\begin{array}{l}\text { Throughout the } \\
\text { stomach }\end{array}$ & Multiple & Biopsy & Absent & $\begin{array}{l}\text { Alive/skin lesion } \\
\text { developed }\end{array}$ & $2 \mathrm{yr}$ \\
\hline 7 & Present case & $64 / \mathrm{M}$ & Asymptomatic & Elevated & Fundus & Solitary & Biopsy, ESD & Absent & Remission & $6 \mathrm{mo}$ \\
\hline
\end{tabular}

M, male; F, female; R/O, rule out; N/A, not applicable; ESD, endoscopic submucosal dissection.

aultisystem involvement at diagnosis.

port, ${ }^{4}$ our case showed aggregates of histiocytic cells with Langerhans cell nuclear features, which were mixed with inflammatory cells, mainly eosinophils. Immunohistochemical analysis is helpful to confirm the diagnosis, and Langerhans cells show diffuse immunoreactivity for S100 and CD1a. ${ }^{1,4}$ In such cases, we suggest that stomach LCH could appear as a submucosal tumor upon endoscopy. Pathologists should consider the possibility of LCH if microscopic observation of biopsy specimens reveals increased eosinophilia or histiocytic cells. In these cases, immunohistochemical staining for S100 and CD1a is needed.

\section{Conflicts of Interest}

No potential conflict of interest relevant to this article was reported.

\section{Acknowledgments}

This work was supported by the year 2014 clinical research grant from Pusan National University Hospital.

\section{REFERENCES}

\section{Abla O, Egeler RM, Weitzman S. Langerhans cell histiocytosis: cur-} rent concepts and treatments. Cancer Treat Rev 2010; 36: 354-9.

2. Behdad A, Owens SR. Langerhans cell histiocytosis involving the gastrointestinal tract. Arch Pathol Lab Med 2014; 138: 1350-2.
3. Detlefsen S, Fagerberg CR, Ousager LB, et al. Histiocytic disorders of the gastrointestinal tract. Hum Pathol 2013; 44: 683-96.

4. Singhi AD, Montgomery EA. Gastrointestinal tract langerhans cell histiocytosis: a clinicopathologic study of 12 patients. Am J Surg Pathol 2011; 35: 305-10.

5. Vetter-Laracy S, Salinas JA, Martin-Santiago A, Guibelalde M, Balliu PR. Digestive tract symptoms in congenital langerhans cell histiocytosis: a fatal condition in an illness usually considered benign. J Pediatr Hematol Oncol 2014; 36: 426-9.

6. Iwafuchi M, Watanabe H, Shiratsuka M. Primary benign histiocytosis $X$ of the stomach: a report of a case showing spontaneous remission after $51 / 2$ years. Am J Surg Pathol 1990; 14: 489-96.

7. Nihei K, Terashima K, Aoyama K, Imai Y, Sato H. Benign histiocytosis $\mathrm{X}$ of stomach: previously undescribed lesion. Acta Pathol Jpn 1983; 33: 577-88.

8. Vazquez JJ, Ayestaran JR. Eosinophilic granuloma of the stomach similar to that of bone: light and electron microscopic study. Virchows Arch A Pathol Anat Histol 1975; 366: 107-11.

9. Lee CK, Lee SH, Cho HD. Localized Langerhans cell histiocytosis of the stomach treated by endoscopic submucosal dissection. Endoscopy 2011; 43 Suppl 2: E268-9.

10. Wada R, Yagihashi S, Konta R, Ueda T, Izumiyama T. Gastric polyposis caused by multifocal histiocytosis X. Gut 1992; 33: 994-6. 